\title{
Retrospective Comparison of Moderate and Severe Diaphragmatic Eventration in Children: Efficiency of Radiological Classification
}

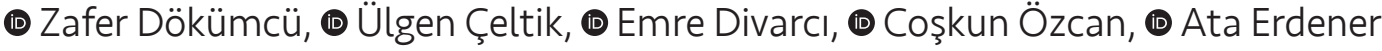

Ege University Faculty of Medicine, Department of Pediatric Surgery, İzmir, Turkey

\begin{abstract}
Aim: Diaphragmatic eventration (DE) is a congenital or acquired elevation of the hemi-diaphragm. The indications for surgery may be challenging because clinical symptoms do not always correlate with radiological severity. We aim to identify the factors for the necessity and the efficiency of thoracoscopic diaphragmatic plication (TDP) in children with DE.

Materials and Methods: A retrospective cross-sectional analysis of patients treated for DE (April 2006-August 2017) was performed. Demographics, type of DE, laterality, associated malformations and clinical symptoms were evaluated. Patients were grouped in two groups (moderate and severe) according to their diaphragmatic elevation levels on $\mathrm{X}$-ray at admission. The severe DE group (SDE, $n=14$ ) had a DE of more than 2 vertebral bodies whereas the $D E$ was 2 vertebral bodies or less in the moderate DE group (MDE, $n=16)$. The groups were then compared regarding the necessity of TDP. The efficiency of TDP was analyzed by comparison of the outcome of patients who underwent TDP with that of conservative management.

Results: There were $30 \mathrm{DE}$ cases with a median age of 13.75 months. DE was acquired in 5 patients. The right side was the dominant side (21/30). The most common clinical symptoms were pneumonia (21) and respiratory distress (7) while 6 cases were asymptomatic. Acquired DE and respiratory distress were significantly higher in the SDE group. Four patients (25\%) in the MDE group and 13 patients (92.9\%) in the SDE group required TDP $(p=0.000)$. The total number of cases of pneumonia was significantly higher in the conservatively treated patients in the follow-up ( $p=0.023)$.

Conclusion: Two vertebral bodies may be an efficient cut-off level to discriminate between MDE and SDE. Absolute indications for TDP are SDE, acquired DE and respiratory distress at admission. Patients that are conservatively treated are more prone to pneumonia.

Keywords: Child, diaphragm, risk factors, thoracoscopy
\end{abstract}

\section{Introduction}

Diaphragmatic eventration (DE) is defined as the elevation of the hemidiaphragm without defects of continuity. The generally accepted concept of its management includes conservative and surgical treatment options for asymptomatic and symptomatic cases respectively. Respiratory symptoms such as pneumonia and dyspnea constitute the common indications for surgical intervention; however, these symptoms do not always correlate with the severity of the pathology and hence the decision for surgery may sometimes be challenging.

Thoracoscopic diaphragmatic plication (TDP) has been performed on children for decades and has been shown to be effective and safe previously (1-3). However, no classification or a surgical approach algorithm has been proposed for this anomaly to date. The purpose of this report is to identify the factors for the necessity and the efficiency of TDP in children with DE. 


\section{Materials and Methods}

\section{Patients}

The study was approved by the Ege University Local Ethics Committee (approval number: 17/7.2), the medical records of children who were diagnosed as DE in a tertiary medical center between April 2006 and August 2017 (n=30) were reviewed. Written consent was obtained for all patients. Records of demographic data, clinical, radiological and operative findings and outcomes were collected.

\section{Radiological Classification and the Comparison of Moderate and Severe Diaphragmatic Eventration}

All patients were retrospectively evaluated and grouped according to the elevation level of the affected hemidiaphragm via X-rays taken at admission. The diaphragm dome height was determined on the postero-anterior radiograph by drawing a horizontal line tangent to the diaphragm dome and extending this to the vertebral column (Figure 1). The expected level of the hemidiaphragm was one vertebral body higher for the right side. Patients with a diaphragmatic elevation of more than the height of 2 vertebral bodies at admission were classified as severe DE group ( $S D E, n=14$ ). The moderate DE group (MDE, $n=16$ ) included those patients admitted with a diaphragmatic elevation of 2 vertebral bodies or less. The groups were then compared regarding their demographics, preoperative findings, indications and outcomes.

\section{Management of Diaphragmatic Eventration}

The eventration of the diaphragm was detected by X-ray in all patients, and paradoxical movement of the diaphragm was confirmed with either fluoroscopy or ultrasonography when needed. All procedures were performed by four boardcertified surgeons via three trocars $(3-5 \mathrm{~mm}$ ) and plications were performed with non-absorbable interrupted sutures (silk 2/0) on the posterolateral-anteromedial axis of the hemidiaphragm in a reefing fashion.

\section{Statistical Analysis}

Continuous variables are presented as mean \pm standard deviation or as median and range where appropriate. Categorical variables are expressed as numbers and percentages and analyzed for comparisons using the Pearson chi-square test. Comparison of groups was performed by univariate analysis using IBM SPSS Statistics 23.0 (IBM Corp., Armonk, NY, USA). Positive predictive values (PPV) and negative predictive values (NPV) for TDP were calculated on crosstabulation of groups (SDE and MDE) with treatment groups (conservative and surgical). The Mann-Whitney $U$ test was used to compare differences in median age at admission, mean follow-up period and number of cases of pneumonia on follow-up.

\section{Results}

\section{Overall Study Group}

There were 30 DE cases (16 boys, 14 girls) with a median age of 13.75 months (2-180 months). DE was acquired due to prior thoracic surgery in 5 patients. The most common associated malformations were cardiac pathologies (4) and pectus carinatum (2) whereas there was also one from each subsequent pathology; Chilaiditi syndrome, thymoma, hydrocephaly, gastroesophageal reflux and corrected hiatal hernia. The right side was the dominant side (21/30). The most common clinical manifestation was pneumonia $(n=21)$. Respiratory distress was evident in 7 cases. Six cases were asymptomatic. At initial admission, there were 16 patients in the MDE group and fourteen patients in the SDE group. These two groups were similar in terms of median age, gender distribution, laterality and associated anomalies. Acquired DE was significantly higher in the SDE group $(p=0.009)$. Clinical symptoms were similar between the groups except for respiratory distress which was slightly higher in the SDE group $(p=0.044)$. Radiologically, mean diaphragmatic elevation at admission was 1.53 and 3.20 for MDE and SDE groups respectively $(p=0.000)$. Atelectasis on computed tomography (CT)-scan showed no significant difference between the groups. Table I depicts the demographics, clinical and radiological characteristics of both groups at admission. The type of DE was the only significant variable; hence a multivariate analysis was not performed. PPV and NPV were calculated for assessment of the effect of patients' characteristics on the type (surgical or conservative) of the management (Table II). For the necessity

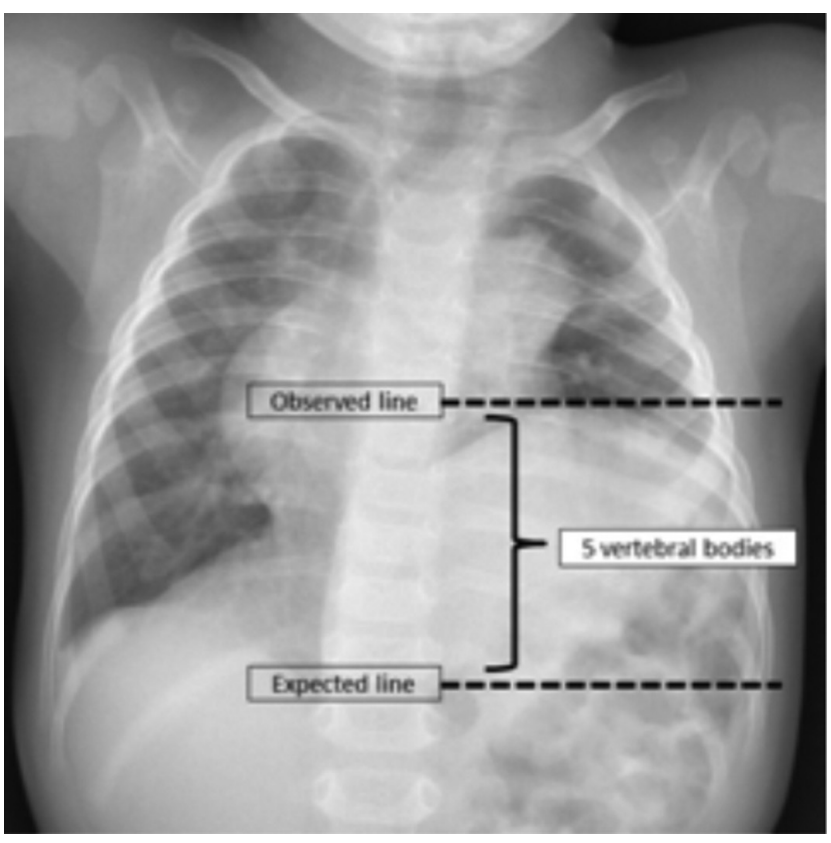

Figure 1. Postero-anterior chest radiograph with measurement of the elevated hemidiaphragm dome-corresponding vertebral body (T9) 


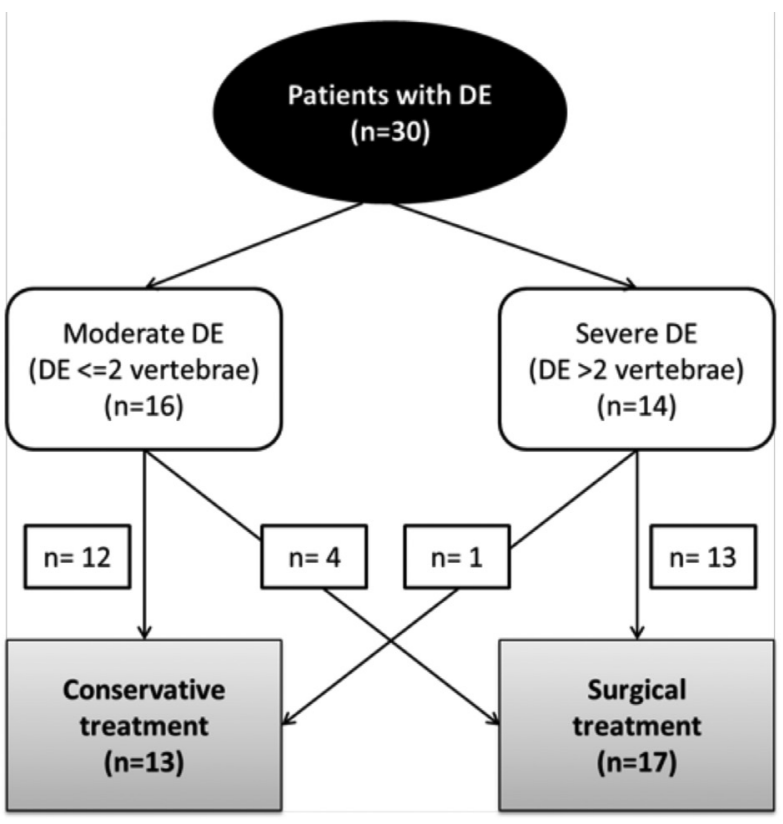

Figure 2. Flowchart of patient groups and outcome DE: Diaphragmatic eventration

of TDP; acquired DE had a PPV of $80 \%(p>0.05)$, respiratory distress had a PPV of $85.7 \%(p=0.017)$ and the presence of atelectasis on CT-scan had a PPV of $90.9 \%(p=0.050)$. Four patients (25\%) in the MDE and thirteen patients (92.9\%) in the SDE groups required TDP $(p=0.000)$. Indications for TDP were pneumonia in 11 and respiratory distress in 6 patients. Three asymptomatic patients with associated malformations (history of thymectomy, pectus carinatum and history of cardiac operation) required TDP later in the course due to developing respiratory distress in 1 case, and severe elevation of the diaphragm (more than 4 vertebral bodies) in 2 cases.

\section{Switching Patients}

Four patients with pneumonia symptoms required TDP in the MDE group. Indications were newly developed respiratory distress and ipsilateral lower lobe atelectasis in 3 cases and a recurrence of pneumonia in 1 case.

In the SDE group, one patient with a previous history of cardiac operation was followed up and did not receive surgical treatment due to the resolution of the eventration in the third postoperative month (Figure 2).

\section{Surgically Treated Patients}

At the end of a median follow-up period of 1 month before surgery, TDP was performed on 17 children (median operation age of 14 months). Major indications were pneumonia in 11 and respiratory distress in 6 patients. Three patients with very SDE (4-5 vertebral bodies) underwent TDP although they were asymptomatic.

All procedures were completed via three trocars $(3-5 \mathrm{~mm})$ with non-absorbable interrupted sutures to create one plication line in the posterolateral-anteromedial axis. Transient pleural

\begin{tabular}{|c|c|c|c|c|}
\hline & & $\begin{array}{l}\text { MDE } \\
(n=16)\end{array}$ & $\begin{array}{l}\text { SDE } \\
(n=14)\end{array}$ & $\mathrm{p}$ value \\
\hline \multicolumn{2}{|c|}{ Median age (months) } & $\begin{array}{l}16.25 \\
(2-180)\end{array}$ & $\begin{array}{l}11.5 \\
(4-156)\end{array}$ & $>0.05$ \\
\hline \multicolumn{2}{|c|}{$\begin{array}{l}\text { Gender } \\
\text { Male } \\
\text { Female }\end{array}$} & $\begin{array}{l}8 \\
8\end{array}$ & $\begin{array}{l}8 \\
6\end{array}$ & $>0.05$ \\
\hline \multicolumn{2}{|c|}{$\begin{array}{l}\text { Type } \\
\text { Congenital } \\
\text { Acquired }\end{array}$} & $\begin{array}{l}16 \\
0\end{array}$ & $\begin{array}{l}9 \\
5 \\
\end{array}$ & 0.009 \\
\hline \multicolumn{2}{|c|}{$\begin{array}{l}\text { Laterality } \\
\text { Right } \\
\text { Left }\end{array}$} & $\begin{array}{l}11 \\
5\end{array}$ & $\begin{array}{l}10 \\
4\end{array}$ & $>0.05$ \\
\hline \multicolumn{2}{|c|}{ Associated malformation } & 3 & 7 & $>0.05$ \\
\hline \multirow{4}{*}{ 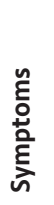 } & Asymptomatic & 3 & 3 & $>0.05$ \\
\hline & Pneumonia & 13 & 8 & $>0.05$ \\
\hline & Respiratory distress & 1 & 6 & 0.044 \\
\hline & Vomiting & 1 & 1 & $>0.05$ \\
\hline \multicolumn{2}{|c|}{$\begin{array}{l}\text { Mean diaphragmatic elevation } \\
\text { (VB) }\end{array}$} & 1.53 & 3.20 & 0.000 \\
\hline \multicolumn{2}{|c|}{ Atelectasis on CT scan } & $4 / 8$ & $7 / 10$ & $>0.05$ \\
\hline
\end{tabular}

MDE: Moderate diaphragmatic eventration, SDE: Severe diaphragmatic eventration, VB: Vertebral body, CT: Computerized tomography

effusion in 2 patients and pneumothorax in 1 patient developed as minor post-operative complications which resolved within a few days. Colonic perforation occurred in one patient with Chilaiditi syndrome (second patient of the series) and this was repaired laparoscopically. The median postoperative hospital stay was four days (3-30 days) for this group.

All patients benefited from surgical intervention clinically and radiologically. There was no recurrence, 4 hospital admissions and 1 episode of postoperative pneumonia in the median postoperative follow-up period of 11 months (6-17 months).

\section{Conservatively Treated Patients}

Thirteen patients were managed conservatively for a median follow-up period of 16 months (2-32 months). Of these, DE persisted at the same level (1 vertebral body above the expected level) in only 2 patients whereas DE was resolved radiologically in the remaining ones. There were 7 hospital admissions and 6 episodes of pneumonia within the follow-up period (Table II).

\section{Discussion}

Thoracoscopic diaphragmatic plication was first reported in 1995 (4). The first pediatric case was performed on a new born in 1998 (5). With the advancement of this minimally 
Table II. Comparison of conservatively treated and surgically treated patients' characteristics and positive predictive value and negative predictive value for the necessity of thoracoscopic diaphragmatic plication

\begin{tabular}{|c|c|c|c|c|c|c|}
\hline \multicolumn{2}{|c|}{ Patient characteristics } & \multirow{2}{*}{ 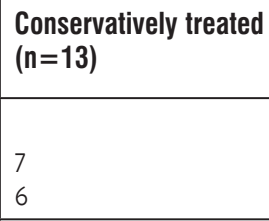 } & \multirow{2}{*}{$\begin{array}{l}\text { Surgically treated } \\
(\mathrm{n}=17)\end{array}$} & \multirow{2}{*}{$\begin{array}{l}\text { PPV for TDP } \\
\\
56.3 \% \\
57.1 \% \\
\end{array}$} & \multirow{2}{*}{$\begin{array}{l}\text { NPV for TDP } \\
\\
42.9 \% \\
43.7 \% \\
\end{array}$} & \multirow{2}{*}{$\begin{array}{l}\text { p value } \\
>0.05\end{array}$} \\
\hline \multirow{9}{*}{.흘 } & $\begin{array}{l}\text { Gender } \\
\text { Male } \\
\text { Female }\end{array}$ & & & & & \\
\hline & $\begin{array}{l}\text { Type of DE } \\
\text { Congenital } \\
\text { Acquired }\end{array}$ & $\begin{array}{l}12 \\
1\end{array}$ & $\begin{array}{l}13 \\
4\end{array}$ & $\begin{array}{l}52 \% \\
80 \%\end{array}$ & $\begin{array}{l}20 \% \\
48 \%\end{array}$ & $>0.05$ \\
\hline & $\begin{array}{l}\text { Laterality } \\
\text { Right } \\
\text { Left }\end{array}$ & $\begin{array}{l}8 \\
5\end{array}$ & $\begin{array}{l}13 \\
4\end{array}$ & $\begin{array}{l}61.9 \% \\
44.4 \%\end{array}$ & $\begin{array}{l}55.6 \% \\
38.1 \%\end{array}$ & $>0.05$ \\
\hline & Associated malformation & 4 & 6 & $60 \%$ & $56.3 \%$ & $>0.05$ \\
\hline & Asymptomatic & 3 & 3 & $50 \%$ & $40 \%$ & $>0.05$ \\
\hline & Pneumonia & 10 & 11 & $52.4 \%$ & $33.3 \%$ & $>0.05$ \\
\hline & Respiratory distress & 1 & 6 & $85.7 \%$ & $50 \%$ & 0.017 \\
\hline & Vomiting & 1 & 1 & $50 \%$ & $42.9 \%$ & $>0.05$ \\
\hline & Atelectasis on CT scan & $1 / 5$ & $10 / 13$ & $90.9 \%$ & $57.1 \%$ & 0.050 \\
\hline \multirow{3}{*}{ 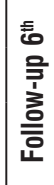 } & Total number of hospital admissions & 7 & 4 & N/A & $\mathrm{N} / \mathrm{A}$ & $>0.05$ \\
\hline & Total number of pneumonia & 6 & 1 & N/A & $N / A$ & 0.023 \\
\hline & Median follow-up period (months) & $\begin{array}{l}16 \\
(2-32)\end{array}$ & $\begin{array}{l}11 \\
(6-17)\end{array}$ & N/A & N/A & $>0.05$ \\
\hline
\end{tabular}

DE: Diaphragmatic eventration, PPV: Positive predictive value, NPV: Negative predictive value, TDP: Thoracoscopic diaphragmatic plication, CT: Computerized tomography, N/A: Not applicable

invasive technique, TDP has become a good alternative for DE (6). However, the number of studies that have investigated minimally invasive surgery for DE is limited. Becmeur et al. (7) presented 18 thoracoscopic pediatric cases in 2005. To date, less than 100 cases have been presented in English literature (Table III). This is the first study to classify DE according to the elevation level of the hemidiaphragm on chest radiography and to evaluate the efficiency of thoracoscopic plication by comparing surgically treated patients with conservatively followed-up cases.

There has been controversy regarding conservative versus surgical treatment for DE. Absolute indications include recurrent life-threatening pneumonia and respiratory distress. A functional deficit of the ipsilateral lung and SDE have also been reported to be an indication for surgical repair (1). However, a functional deficit of the lung and SDE remain controversial due to their subjective nature. What is more, the severity of DE is not always in parallel with clinical symptoms. Some patients are asymptomatic even though the radiological grade of DE is high, and some patients with MDE may develop recurrent pneumonia or respiratory distress, as was seen in our series. Therefore, an algorithm for the management of DE is necessary and is considered in this report.

Minimally invasive diaphragm plication techniques have emerged as equally effective and less morbid alternatives to open plication. When it is considered that the lungs continue to grow until the age of nearly ten years, surgical therapy seems reasonable to provide space for future pulmonary development (2). We have preferred surgical repair in patients with SDE who present with pneumonia and respiratory distress. In grey zone patients with MDE, the decision for surgery has been made according to the presence of atelectasis in the ipsilateral lower lobe on CT-scan. Our results indicate that radiological classification with a cut-off level of two vertebral bodies is efficient. What is more, the surgically treated group benefited from the treatment in terms of their postoperative outcomes whereas the conservatively treated patients seemed to be more prone to pneumonia although they had less SDE. Hence, we think that patients with SDE should undergo TDP without delay. Acquired DE is the only exception to performing early TDP. Although it is frequently necessary (PPV for TDP was as high as $80 \%$ in acquired DE in our series), phrenic nerve injury may spontaneously recover within 6 weeks as has been previously reported $(6,8,9)$. We prefer to observe these patients for at least three months following surgical trauma. There were five acquired DE cases in our study group out of which 4 (3 cardiac surgery, one thymectomy) required TDP and one had resolved without plication by the $3^{\text {rd }}$ month of follow-up. DE symptoms may range from wheezing to lifethreatening respiratory distress requiring mechanical ventilator 
Dökümcü et al.

Which Patients Require Thoracoscopic Diaphragmatic Eventration?

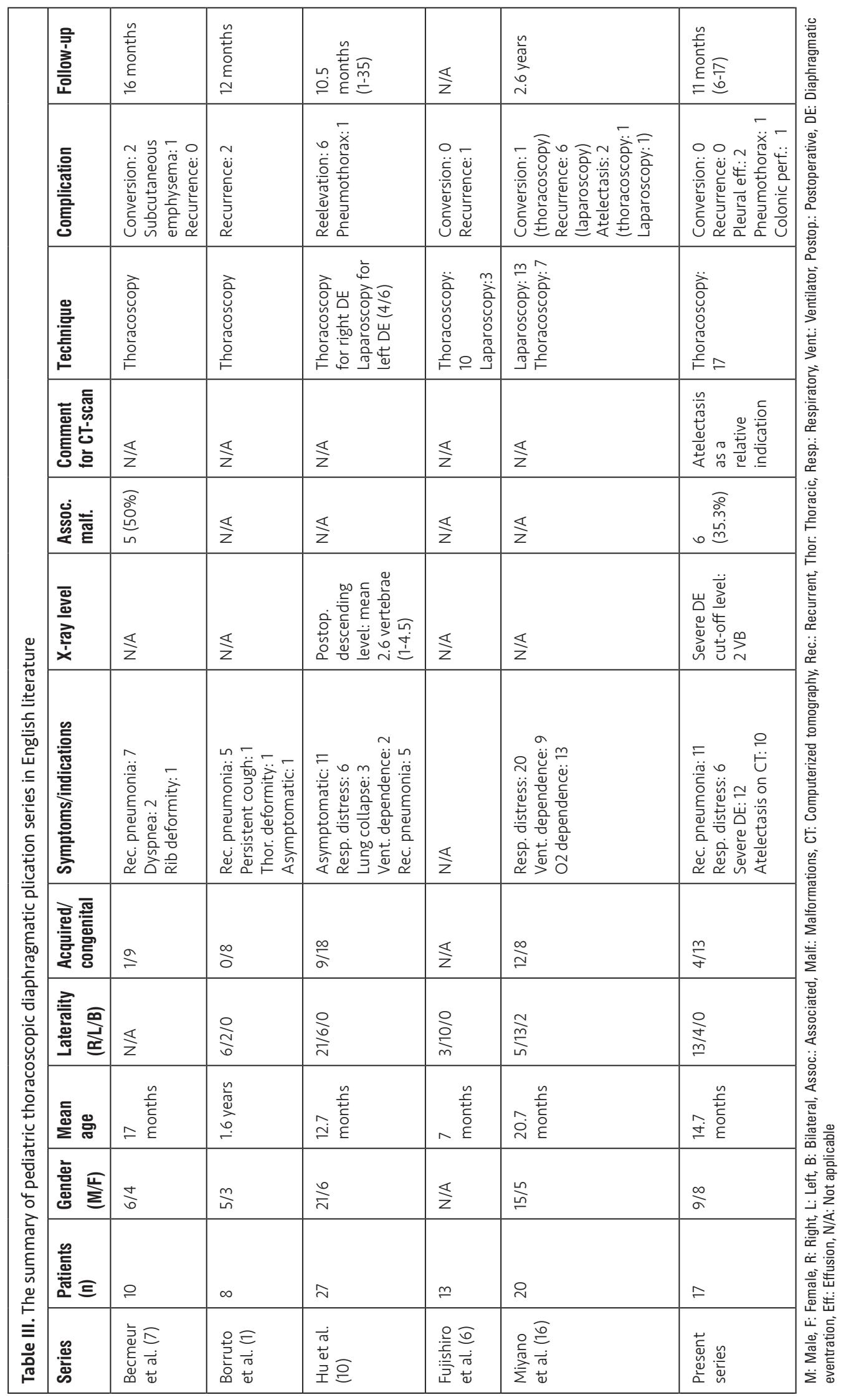


support in small children or frequent respiratory infections and exercise intolerance in older children (2). Some investigators suggest that very severe eventration that occupies much of the hemi-thorax should be repaired on that basis alone for fear that they might interfere with postnatal lung development (3). Indeed, symptoms do not correlate with the severity of DE as in some of our cases. There were six asymptomatic patients with an elevation of the affected hemidiaphragm up to 5 vertebral bodies. In contrast, lower lobe atelectasis was detected in 4 MDE patients with an elevation of the diaphragm of less than two vertebral bodies in our series.

Acquired DE and respiratory distress were the only two variables to be found to significantly affect the outcome in our series. All thoracoscopic procedures were performed successfully. Postoperative minor complications included two pleural effusions and one pneumothorax. There was a colonic perforation in a patient with right DE and Chilaiditi syndrome. After the plication procedure, immediate remission of symptoms was noted in our patients. Minimal access surgery may offer a more rapid improvement with a shorter recovery period $(1,10-12)$. The principle of the operation is to decrease the surface of the redundant diaphragm by plicating it to an acceptable level. In this way, the repair improves the movement of the diaphragm during respiration and achieves physiologic pulmonary function. The global muscular force of the diaphragm increases after unilateral plication with a gain of $30 \%$ in trans-diaphragmatic pressure $(13,14)$. Literature reports several experiences about the efficiency and safety of thoracoscopy in the treatment of DE in terms of less ventilation impact and better outcomes (7,10-12,14-16). The duration of the procedure was not longer than open surgery. In our department, thoracoscopic plication is preferred as the gold standard operation for the treatment of DE.

\section{Conclusion}

We consider that TDP is efficient in cases of DE. It offers all the benefits of minimal-invasive surgery with significantly better respiratory outcomes compared to conservative management. Early thoracoscopic plication should be considered for children with absolute indications including $\mathrm{SDE}$, acquired DE (following observation for at least 3 months) and respiratory distress. Relative indications are MDE with a history of pneumonia and the presence of atelectasis on CT-scan.

\section{Acknowledgement}

We would like to thank Assoc. Prof. Timur Köse for his assistance in the statistical analysis.

\section{Ethics}

Ethics Committee Approval: The study was approved by the Ege University Local Ethics Committee (approval number: $17 / 7.2)$
Informed Consent: Consent form was filled out by all participants.

Peer-review: Externally peer-reviewed.

\section{Authorship Contributions}

Surgical and Medical Practices: Z.D., E.D., C.Ö., A.E., Concept: Z.D., Design: Z.D., Data Collection or Processing: Ü.Ç., E.D., Analysis or Interpretation: Z.D., Ü.Ç., E.D., Literature Search: Z.D., E.D., Writing: Z.D.

Conflict of Interest: No conflict of interest was declared by the authors.

Financial Disclosure: The authors declared that this study received no financial support.

\section{References}

1. Borruto FA, Ferreira CG, Kaselas C, et al. Thoracoscopic treatment of congenital diaphragmatic eventration in children: lessons learned after 15 years of experience. Eur J Pediatr Surg 2014;24:328-31.

2. Tsugawa C, Kimura K, Nishijima E, Muraji T, Yamaguchi M. Diaphragmatic eventration in infants and children: is conservative treatment justified? J Pediatr Surg 1997;32:1643-4.

3. Flageole H. Central hypoventilation and diaphragmatic eventration: diagnosis and management. Semin Pediatr Surg 2003;12:38-45.

4. Gharagozloo F, McReynolds SD, Snyder L. Thoracoscopic plication of the diaphragm. Surg Endosc 1995;9:1204-6.

5. Van Smith C, Jacobs IP, Burke RP. Minimally invasive diaphragm plication in an infant. Ann Thorac Surg 1998;65:842-4.

6. Fujishiro J, Ishimaru T, Sugiyama $M$, et al. Thoracoscopic plication for diaphragmatic eventration after surgery for congenital heart disease in children. I Laparoendosc Adv Surg Tech A 2015;25:348-51.

7. Becmeur F, Talon I, Schaarschmidt K, et al. Thoracoscopic diaphragmatic eventration repair in children: about 10 cases. I Pediatr Surg 2005;40:1712-5.

8. Tönz M, von Segesser LK, Mihaljevic T, Arbenz U, Stauffer UG, Turina Ml. Clinical implications of phrenic nerve injury after pediatric cardiac surgery. I Pediatr Surg 1996;31:1265-7.

9. Joho-Arreola AL, Bauersfeld U, Stauffer UG, Baenziger O, Bernet V. Incidence and treatment of diaphragmatic paralysis after cardiac surgery in children. Eur J Cardiothorac Surg 2005;27:53-7.

10. Hu J, Wu Y, Wang I, Zhang C, Pan W, Zhou Y. Thoracoscopic and laparoscopic plication of the hemidiaphragm is effective in the management of diaphragmatic eventration. Pediatr Surg Int 2014;30:19-24.

11. Hines MH. Video-assisted diaphragm plication in children. Ann Thorac Surg 2003;76:234-6.

12. Abraham MK, Menon SS, S BP. Thoracoscopic repair of eventration of diaphragm. Indian Pediatr 2003;40:1088-9.

13. Kizilcan F, Tanyel FC, Hiçsönmez A, Büyükpamukçu N. The longterm results ofdiaphragmatic plication. J Pediatr Surg 1993;28:42-4.

14. Kaseda S, Aoki T, Hangai N, Shimizu K. Better pulmonary function and prognosis with video-assisted thoracic surgery than with thoracotomy. Ann Thorac Surg 2000;70:1644-6.

15. Fujishiro I, Ishimaru T, Sugiyama $M$, et al. Minimally invasive surgery for diaphragmatic diseases in neonates and infants. Surg Today 2016;46:757-63.

16. Miyano G, Yamoto $M$, Kaneshiro $M$, et al. Diaphragmatic eventration in children: laparoscopy versus thoracoscopic plication. I Laparoendosc Adv Surg Tech A 2015;25:331-4. 